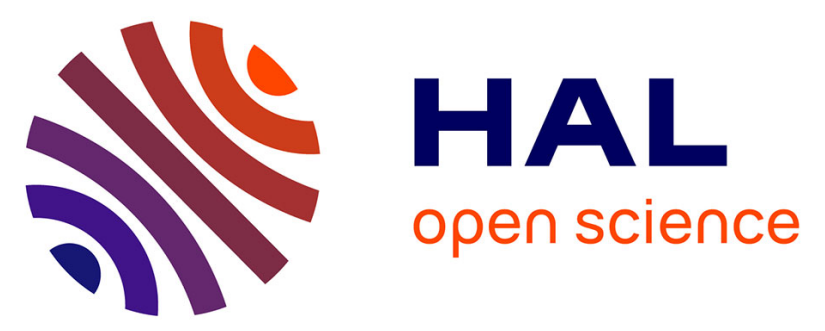

\title{
COLLECTIVE EXCITATIONS IN CHARGED SUPERCONDUCTORS BELOW Tc AND THE LONGITUDINAL ULTRASONIC SPECTRUM
}

\author{
M. Dinter
}

\section{- To cite this version:}

M. Dinter. COLLECTIVE EXCITATIONS IN CHARGED SUPERCONDUCTORS BELOW Tc AND THE LONGITUDINAL ULTRASONIC SPECTRUM. Journal de Physique Colloques, 1978, 39 (C6), pp.C6-470-C6-471. 10.1051/jphyscol:19786210 • jpa-00217630

HAL Id: jpa-00217630

https://hal.science/jpa-00217630

Submitted on 1 Jan 1978

HAL is a multi-disciplinary open access archive for the deposit and dissemination of scientific research documents, whether they are published or not. The documents may come from teaching and research institutions in France or abroad, or from public or private research centers.
L'archive ouverte pluridisciplinaire HAL, est destinée au dépôt et à la diffusion de documents scientifiques de niveau recherche, publiés ou non, émanant des établissements d'enseignement et de recherche français ou étrangers, des laboratoires publics ou privés. 


\title{
COLLECTIVE EXCITATIONS IN CHARGED SUPERCONDUCTORS BELOW T $c$ AND THE LONGITUDINAL ULTRASONIC SPECTRUM
}

\author{
M. Dinter ${ }^{*}$ \\ Department of Physics, University of California, Santa Barbara, Califormia 93106, USA
}

\begin{abstract}
Résumé.- En plus du premier son, un deuxième maximum peut être observé dans le spectre des frêquences acoustiques des métaux supraconducteurs à températures plus basses que $I_{C}$. Il est excité par les mouvements collectifs des électrons, qui influencent aussi le son habituel. La discussion se restreint au cas des spécimens purs. En ce cas la vitesse du nouveau mode est plus grande que celle du premier son.
\end{abstract}

Abstract.- Collective modes in superconductors lead to a second peak in the ultrasonic spectrum besides the first sound maximum, which is also affected. The discussion is restricted to the case of clean samples, in which case the velocity of the new mode is larger than that of ordinary sound.

Collective excitations in charged superconductors near the critical temperature /1-4/ play a role in tunnel junctions, where they govern the fluctuating part of the current-voltage characteristic

Other kinds of experiments revealing the influence of these modes involve density fluctuations of both superfluid and normal electrons by way of the longitudinal dielectric function $\varepsilon^{5}$. Im $1 / \varepsilon$ (related to the scattering cross section of electromagnetic waves and charged particles) has the following property in the dirty limit : At the same frequency $\omega=\sqrt{2 D \Delta q}$ (D the electron diffusion constant, $\Delta$ the pair potential), where there is a maximum in the phase correlation function of the order parameter, characterizing the propagating collective mode, Im $1 / \varepsilon$ has a minimum. Both maximum and minimum disappear, when the superconductor becomes gapless. In the clean limit /5/ that feature is even more pronounced, this time at $\omega=\mathrm{q} \sqrt{2 \mathrm{~A} \Delta} / 6 /$, where $A=7 \zeta$ (3) $\mathrm{v}^{2} /\left(6 \mathrm{~T}^{3} \mathrm{~T}\right)$ with Fermi velocity $\mathrm{v}$ and temperature $\mathrm{T}$. Therefore and on account of complications arising from the collision drag effect in dirty probes, the discussion is confined to clean superconductors.

$\varepsilon$ is in this case (for $\omega \leqslant 2 \Delta<<T$, vq $<<T$ and $q^{<<}$Fermi momentum) :

$$
\begin{aligned}
\varepsilon(\mathrm{q}, \omega) & \doteq 1+\frac{\mathrm{K}^{2}}{\mathrm{q}^{2}}\left(1-\frac{\omega}{2 v q} \mathrm{ln}\left|\frac{\omega+v q}{\omega-v q}\right|\right)+\frac{i \pi \omega K^{2}}{2 v q^{3}} \oplus(v q-\omega)+ \\
& +\frac{\frac{n_{s}}{n} \cdot \omega_{p}^{2}}{-\omega^{2}+A q^{2} \sqrt{4 \Delta^{2}-\omega^{2}}}
\end{aligned}
$$

* On leave of absence from Technische Universitat München.
The last term describes the contribution by the superfluid component, $n_{s} / n=7 \zeta(3) \Delta^{2} /(2 \pi T)^{2}$ is the ratio of superfluid and total particle density, $\Delta^{2}=$ $8 \pi^{2} T^{2}\left(1-T / T_{c}\right) / 7 \zeta(3), \quad \omega_{p}^{2}=4 \pi e^{2} \pi / m$ is the square of the electron plasma frequency. For $\omega \geq 2 \Delta$ replace $\sqrt{4 \Delta^{2}-\omega^{2}}$ by $-i \sqrt{\omega^{2}-4 \Delta^{2}}$. The remaining part of $\varepsilon$ is due to the normal component and the same one is acquainted with from standard literature $\cdot \kappa^{-2}=\mathrm{v}^{2}$ / $3 \omega^{2}$ is the square of the Debye screening radius. Restricting frequencies to $\omega<<2 \Delta<<v q$, wavevectors to $\mathrm{q}<<\mathrm{K}$ we may go ahead simplifying :

$\varepsilon(q, \omega) \approx \frac{k^{2}}{q^{2}}\left(1+\frac{i \pi \omega}{2 v q}\right)+\frac{n_{s}}{n} \frac{\omega_{p}^{2}}{-\omega^{2}+2 A \Delta q^{2}}$

To include the ionic motion within the frame of the jellium model, substract $\Omega_{p}^{2} / \omega^{2}$ from the electronic $\varepsilon$ of (2). $17 / \Omega_{\mathrm{p}}^{2}=4 \pi(\mathrm{Ze})^{2} \mathrm{~N} / \mathrm{M}$ is the square of the ionic plasma frequency. Thus the Coulomb potential between electrons, screened by the combined motion of ions, normal and superfluid electrons, reads :

$D(q, \omega)=-\frac{4 \pi e^{2}}{q^{2}\left(\varepsilon-\Omega_{p}^{2} / \omega^{2}\right)}$

Abbreviations : the velocity of ref. $/ 6 / c=\sqrt{2 A \Delta}$, fourth sound $c_{4}=v \sqrt{\frac{\Omega_{s}}{3 n}}$, first sound $c_{s}=\Omega_{p} / k$ and the square of the electron-phonon coupling cons$\tan t \mathrm{~g}^{2}=4 \pi \mathrm{e}^{2} / \mathrm{K}^{2}$. This essentially yields the phonon Green's function :

$D(q, \omega)=\frac{g^{2} \omega^{2}}{-\omega^{2}+c_{s}^{2} q^{2}-\frac{i \pi \omega^{3}}{2 v q}-\frac{c_{4}^{2} q^{2} \omega^{2}}{-\omega^{2}+c^{2} q^{2}}}$ 


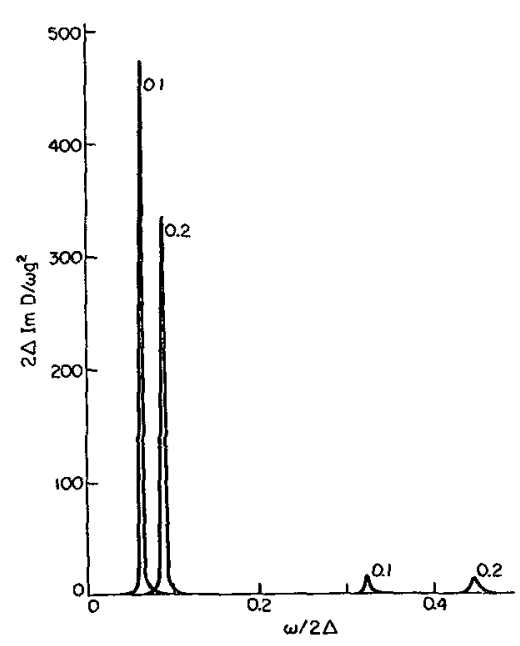

Fig. 1 : U1trasonic spectrum as a function of the temperature dependent scaled frequency $\omega / 2 \Delta$ for two values of the parameter $\mathrm{Aq}^{2} / 2 \Delta(0.1$ and 0.2$)$. The other parameter appearing in formula (4) is fixed $\pi \Delta / 4 T=0.1$. The two peaks on the left are ordinary sound, the small ones at higher frequencies are caused by collective excitations and only present below $\mathrm{T}_{\mathrm{c}}$.

The imaginary part of $D$ is plotted in the figure : besides the first sound peak $\omega \approx c_{s} q$ there is a second maximum at $\omega \approx \mathrm{cq}$, some orders of magnitude smaller, looking like second sound /3/. The denominator of $\mathrm{D}$ yields the spectral equation $(x=\omega / q):$

$\left(x^{2}-c_{s}^{2}+\frac{i \pi x^{3}}{2 v}\right)\left(x^{2}-c^{2}\right)=c_{4}^{2} x^{2}$

Note : $c_{S}^{2}: c_{4}^{2}: c^{2} \approx 10^{-4}:\left(1-T / T_{c}\right):\left(1-T / T_{c}\right)^{1 / 2}$. For the range $10^{-8} \ll 1-T / T_{C} \ll 1 \quad c$ is 1argest of all three velocities; here we get the following spectrum :

$\omega \approx q \sqrt{c^{2}+c_{4}^{2}}-i q \frac{\pi c c_{4}^{2}}{4 v \sqrt{c^{2}+c_{4}^{2}}}, c-s o u n d$ $\omega \approx c_{s} q \frac{c}{\sqrt{c^{2}+c_{s}^{2}+c_{4}^{2}}}-i q \frac{\pi c_{s}^{2}}{4 v} \cdot \frac{c^{4}\left(c^{2}+c_{4}^{2}\right)}{\left(c^{2}+c_{s}^{2}+c_{4}^{2}\right)^{3}} \quad$ sound

From the imaginary part of Lorentz shaped peak one may infer their height, thus finding for the ratio of the two intensities

$\frac{I_{c}}{I_{c_{s}}}=\frac{c_{s}^{2}}{c_{4}^{2}} \cdot \frac{c^{3}\left(c^{2}+c_{4}^{2}\right)^{3 / 2}}{\left(c^{2}+c_{s}^{2}+c_{4}^{2}\right)^{3}} \approx \frac{c_{s}^{2}}{c_{4}^{2}}$

The smaller $1-T / T_{c}$, the better the c-signa1. It may be detected by light, though Brillouin scattering in solids is not easy. Another possibility is ultrasound with frequencies $\omega \approx 10^{10} \mathrm{~s} .^{-1}$ and wavevectors $q \approx 10^{2} \mathrm{~cm}^{-i}$. The attenuation coefficient $\alpha=2 \mathrm{Im}$ $q(\omega)$ describing the exponential decay of the energy intensity is for the $c$-mode $\frac{\pi \omega}{2 v} \cdot c_{4}^{2} c /{\sqrt{c^{2}+c_{4}^{2}}}^{3}$ $\approx(\pi \omega / 2 v) \cdot(\pi \Delta / 4 T)$. For first sound in the normal state at $T_{c}$ it is $\alpha_{n}=\pi \omega / 2 v$. Then (6) yields for the first sound :

$$
\frac{\alpha_{s}}{\alpha_{n}}=\frac{c^{2}\left(c^{2}+c_{4}^{2}\right)}{\left(c^{2}+c_{s}^{2}+c_{4}^{2}\right)^{2}} \approx 1-\frac{\pi \Delta}{4 T}
$$

The BCS prediction (without collective excitations) reads

$$
\frac{\alpha_{s}}{\alpha_{n}}=2 /\left(1+e^{\Delta / T}\right) \approx 1-\frac{\Delta}{2 T}
$$

Due to the propagating mode $\alpha_{\mathrm{s}} / \alpha_{\mathrm{n}}$ drops more rapidly near $\mathrm{T}_{\mathrm{c}}$ than found by BCS. For $1-\mathrm{T} / \mathrm{T}_{\mathrm{c}} \ll 10^{-8}$ one gets $\alpha_{\mathrm{s}} / \alpha_{\mathrm{n}} \approx 1+\mathrm{c}_{4}^{2} \mathrm{c}^{2} / \mathrm{c}_{\mathrm{s}}^{4} \approx 1+10^{8}\left(1-\mathrm{T} / \mathrm{T}_{\mathrm{c}}\right)^{3 / 2}$ : the attenuation coefficient is continuous at and has a maximum below $T_{c}$, which, however, cannot be seen. The hospitality of the Department of Physics of the University of California, Santa Barbara, is gratefully acknowledged. The work has been supported by a research grant from the Deutsche Forschungsgemeinschaft.

\section{References}

/1/ Car1son, R.V. and Goldman, A.M., J.Low Temp. Phys. 25 (1976) 67

/2/ Schmid, A. and Schön, G. Proc.14th Int.Conf.Low Temp.Phys., M. Krusius and M. Vuorio, eds. (North-Holland, Amsterdam) Vol.5, p. 457

/3/ Bray, A.J. and Schmidt, H., Solid State Commun. 17 (1975) 1175

14/ Dinter, M., "Superconductor Fluctuations in Tunneling Junctions Below the Transition Temperature", preprint, to appear in J.Low Temp. Phys. 32

/5/ Dinter, M., J.Low Temp.Phys. 26 (1977) $39 ; \underline{29}$ (1977) 43

/6/ Artemenko, S.N. and Volkov, A.F., Sov.Phys.JETP 42 (1976) 896

/7/ Abrikosov, A.A., Corkov, L.P. and Dzyaloshinski, I.E., "Methods of Quantum Field Theory in Statistical Physics" (Prentice-Ha1l, 1964) 